\title{
STUDY OF CROPPING SYSTEMS DYNAMICS IN THE LOWER GANGETIC PLAINS OF INDIA USING GEOSPATIAL TECHNOLOGY
}

\author{
K.R. Manjunath*, Nitai Kundu, S.S. Ray ${ }^{1}$, Sushma Panigrahy, and J.S. Parihar \\ Earth, Ocean, Atmosphere, Planetary Sciences and Applications Area (EPSA) \\ Space Applications Centre, Ahmedabad 380015 \\ krmanjunath@sac.isro.gov.in \\ ${ }^{1}$ Commission VIII, WG VIII/6
}

KEYWORDS: Cropping pattern, crop rotation, Cropping system, West Bengal, Performance indices

\begin{abstract}
S
Cropping system study is useful to understand the overall sustainability of agricultural system. Capturing the change dynamics of cropping systems, especially spatial and temporal aspects, is of utmost importance in overall planning and management of natural resources. This paper highlights the remote sensing based cropping systems change-dynamics assessment. Current study is aimed at use of multidate-multisensor data for deriving the seasonal cropping pattern maps and deriving the remote sensing based cropping system performance indicators during 1998-99 and 2004-05 in West- Bengal state of India. The temporal assessment of the changes of cropping systems components such as cropping pattern and indices for the study years 1998-99 and 2004-05 have been brought out. The results indicate that during the six years of time the kharif cropping pattern has almost remained the same, being a rice dominant system. A notable point is the decrease in the aus rice due to readjusting the cropping system practice to suit the two crop systems in many places was observed. Marginal variations in mustard and wheat areas during rabi season was observed. The boro (summer) rice area has almost remained constant. The rice-fallow-fallow (R-F-F) rotation reduced by about 4 percent while the rice-fallow-rice (R-F-R) increased by about 7 percent percent. The Area Diversity Index reduced by about 38 percent in 2004 which may be attributed to decrease in kharif pulses and minor crops during kharif and summer. However, diversity during rabi season continued to remain high. The increase in Multiple Cropping Index was observed predominantly in the southern part of the state. Cultivated Land Utilization Index shows an increase by about 0.05 .
\end{abstract}

\section{INTRODUCTION}

A cropping system is defined as the cropping pattern and its management to derive benefits from a given resource base under a specific environmental condition. The important component of cropping system is the cropping pattern which is influenced by variant and invariant resources apart from management practices. The efficiency of such a system can be measured by its performance through indices. The cropping systems approach would require identification of crops and areas where changes in cropping patterns are desirable. This calls for an initial step of creating an updated database of the present cropping systems of the country. The study of this dynamic phenomenon over a period of time would enable the understanding of the long-term effects, taking into consideration the resource base and agroclimatic condition. Satellite remote sensing (RS) and Geographical Information System have a crucial role to play in this direction. The multidate satellite data is helpful in deriving seasonal cropping pattern, sowing pattern, crop rotation, efficiency indicators and other related parameters.

Cropping pattern is defined as the yearly sequence and spatial arrangement of crops or of crops and fallow on a given area. Growing two, three or four crops in a year is defined as double, triple and multiple cropping. The repetitive cultivation of an ordered succession of crops (or crop and fallow) on the same land is defined as crop rotation. One cycle may take one or more years to complete. It defines crop intensification in time dimension. The succeeding crop is planted after the preceding crop is harvested.

Information System (GIS). Crop rotation mapping using IRS data was first demonstrated in India by Panigrahy and Sharma (1997). Spatial database of parameters like crop area, cropping pattern, crop rotation, crop calendar, crop vigour etc. was created using multi-temporal and multi-spectral data. Capturing the temporal dynamics of vegetation requires series of observations of the same area. The multidate optical data such as IRS AWiFS/WiFS are is ideal for deriving the rabi and summer cropping pattern. The cropping system analysis has been demonstrated for Indogangetic plains (Panigrahy et al., 2009). The outputs generated in the study were seasonal cropping pattern, crop rotation, kharif fallow area maps as well as crop intensification and diversity maps. The cropping systems performance indicators were also generated. Cropping systems is often subjected to change owing to several factors such as farmer's preference, environmental modifications, technological advances and also market driven. Capturing the change dynamics of cropping systems, especially spatial and temporal aspects, is of utmost importance in overall planning and management of natural resources. This calls for not only mapping the various aspects of cropping systems i.e. seasonal cropping pattern but also assessment of cropping systems performance indicators.

This paper highlights the results of a study carried out towards cropping system derivation and change dynamics in West Bengal 
state, the lower Indo-Gangetic plain region of India. There were two aspects of the study. The first aspect included district level cropping system mapping using multi-date remote sensing data. The second part is to evaluate the system using various indices derived using moderate spatial resolution high temporal remote sensing data. We derived the cropping system components and indices twice (1998-99 and 2004-5) and compared the findings to assess the change dynamics between the study periods.

\section{MATERIALS AND METHODS}

\subsection{Study area}

The West Bengal state of India is the study area. The state of West Bengal covers geographical area of 8686.63 thousand hectares and lies in the eastern coast of India between $21^{\circ} 45^{\prime}$ to $26^{\circ} 45^{\prime} \mathrm{N}$ latitude and $86^{\circ}$ to $90^{\circ} \mathrm{E}$ longitudes. The state of West Bengal is divided into 21 districts. In general, the geography of West Bengal is diverse, consisting of high peaks of Himalaya in the northern extremes to coastal regions down south, with regions such as plateau and Ganges delta intervening in between. Agriculture plays a pivotal role in the State's income and nearly three out of every four persons are directly or indirectly involved in agriculture. Principal crops grown in the state are rice, wheat, jute, potato and oilseeds. Around 66.9 per cent of the total geographical area (TGA) of the state is under cultivation. Area under forest cover is 13.52 per cent of TGA in the state, while the remaining 19.57 per cent of TGA in the state is under permanent fallow/wastelands/settlements /built-up etc. The state has a large chunk of area cultivated in three seasons i.e. kharif, rabi and summer (cropping intensity, 148 per cent). In West Bengal state, almost 55 per cent of the net area sown (NAS) is irrigated.

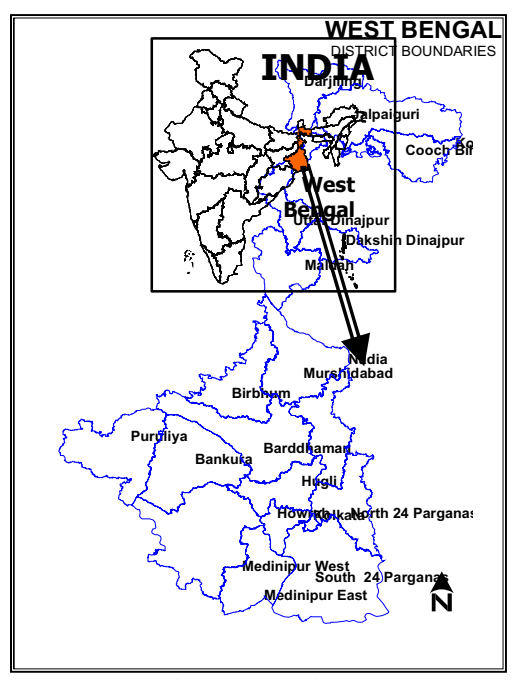

Fig. 1: Location map of West Bengal state

\subsection{Data used}

The study aimed at deriving maximum possible information about crops. Hence, attempt has been made to use remotely sensed data acquired throughout the crop-growing year. The remote sensing data used in this study fall in two categories based on the part of electromagnetic spectrum they cover: (i). Optical remote sensing, and (ii). Microwave remote sensing data. The optical data used in for cropping system analysis was multi-temporal Resourcesat-1 (IRS-P6) Advanced Wide Field Sensor (AWiFS) data for the year 2004-05 while IRS-1C WiFS (Wide Field Sensor) data was used during 1998-99. The details of WiFS/AWIFS sensor are presented in Table 1.

WiFS/AWiFS sensor has the capability of providing data at 5 days interval with a wide swath of $810 / 740 \mathrm{~km}$. This data acquired from October 2004 to May 2005 were used in this study to map the crops grown in Rabi and summer season. The optimum coverage scenes were selected through browsing with different path/row combinations over the study area to screen out the cloud free scenes. West Bengal is optimally covered by AWiFS scene $106 / 54$ while it was covered in two scenes of WiFS.

\begin{tabular}{|l|l|l|}
\hline Parameter & AWiFS & WiFS \\
\hline $\begin{array}{l}\text { Spectral Band } \\
(\mathrm{nm})\end{array}$ & B2: 520-590 (Green); & B3: 620-680 (Red); \\
& B4: 770-860 (NIR); & $0.62-0.68(\mathrm{R})$ \\
B5: $1550-1700$ (SWIR) & $0.77-0.86$ (NIR) \\
\hline $\begin{array}{l}\text { Spatial } \\
\text { Resolution }\end{array}$ & $56 \mathrm{~m}$ & 188 \\
\hline $\begin{array}{l}\text { Radiometric } \\
\text { Resolution }\end{array}$ & $10 \mathrm{bit}$ & 7 \\
\hline $\begin{array}{l}\text { Temporal } \\
\text { Resolution }\end{array}$ & 5 days & 5 days \\
\hline Swath-width & $740 \mathrm{~km}$ & 810 \\
\hline
\end{tabular}

Table 1: Specifications of Resourcesat-1 AWiFS sensor

Three-date Synthetic Aperture Radar (SAR) data from RADARSAT of ScanSAR (Table 2) narrow beam mode acquired during July-September during 1998 and 2004 were used to derive kharif season cropping pattern, as cloud-free data from optical sensors is rarely available during this period. ScanSAR narrow beam data has $50-\mathrm{m}$ resolution and a swath of $300 \mathrm{~km}$, and repeat cycles of 24 days. These data have been found suitable for large area rice crop monitoring and are used operationally in India for kharif rice crop acreage estimation (Panigrahy et al. 2009).

\begin{tabular}{|l|c|c|c|}
\hline $\begin{array}{l}\text { Incidence Angle } \\
\text { (Degree) }\end{array} \quad$ Mode & W2 & S5 & S6 \\
\hline $\begin{array}{l}\text { Beam } \\
\text { Combinations }\end{array}$ & $55.1 * 71.1$ & $50.1 * 71.9$ & $45.7 * 78.8$ \\
\hline $\begin{array}{l}\text { Resolution } \\
\text { (Range*Azimuth) m }\end{array}$ & \multicolumn{3}{|c|}{350} \\
\hline Nominal Swath (km) & Table 2: Specifications of RADARSAT ScanSAR Narrow-2 data \\
\hline
\end{tabular}

In order to compute the efficiency indices, especially the cultivated land utilization index, we need crop duration. For this purpose we collected crop duration information from field observations. During 2004-5 high temporal resolution of SPOTvegetation sensor ten-day cumulative NDVI (Normalized 
Difference Vegetation Index) product was used. NDVI is computed as: $(\mathrm{NIR}-\mathrm{R}) /(\mathrm{NIR}+\mathrm{R})$, wherein NIR and $\mathrm{R}$ are reflectance in near infrared and red bands. The vegetation optical instrument on-board SPOT satellite of the French Space Agency operates in four spectral bands: blue, red and near infrared, and short wave infrared (SWIR), having a spatial resolution of $1 \mathrm{~km}$. The ten-day composite NDVI products are available free on the Internet (www.free.vgt.vito.be). The data set comprising 39 dates starting from May 11, 2004 to May 21, 2005 were used.

\subsection{Collateral data}

District level Agricultural Statistics provided by department of economics and statistics of the state was used for comparing the agricultural land use statistics. Ground truth and in-situ measurements are important inputs for remote sensing data analysis. They are used to classify the data and obtain various thematic layers as well as to verify the accuracy of the outputs obtained. Ground truth was collected during different seasons by visiting the fields and recording the crop/ land cover information at selected sites. Global Positioning System (GPS) and SOI topographic maps on $1: 50,000$ scale, were used to record the geographic coordinates of ground truth sites.

\subsection{Methodology}

2.4.1 Cropping system mapping using remote sensing data This methodology is primarily based on the use of digital image analysis techniques. Various components of the methodology are: i) Creation of RS database, ii) image classification pre-processing of remote sensing data, iii) Generation of cropping pattern and crop rotation etc.

2.4.2 Creation of RS database: The WiFS/AWiFS data were used as prime image dataset for the cropping system analysis. The WiFS data base was created at $188 \mathrm{~m}$ spatial resolution for analysis of 1998-99 data while AWiFS data of $56 \mathrm{~m}$ spatial resolution was selected as the prime image dataset for the year 2004-5 and database at $50 \mathrm{~m}$ spatial resolution was created.. Around eight dates $\mathrm{WiFS} / \mathrm{AWiFS}$ data scenes (keeping in view of the crop calendar of the area), were needed to be stacked for the study area. The data were georeferenced (Projection :Transverse Mercator, Earth Model: WGS84) and stacked. Apart from AWiFS data, multi-date Synthetic Aperture Radar data from the ScanSAR beam mode of Canadian satellite RADARSAT was used. A stack of three dates of this data were prepared as per the procedure given by Chakraborty and Panigrahy (2000). After preparing the stack of SAR data it was registered with AWiFS tile by taking 1012 GCPs and following Nearest Neighbourhood resampling approach and $2^{\text {nd }}$ order polynomial model.

2.4.3 Image Classification: Multidate image classification was carried out for generating seasonal cropping patterns. The nonagricultural classes in the image included: forest, wasteland, water bodies, urban/settlement and permanent vegetation. In the beginning water bodies and urban/settlement were classified using three date SAR data. Water bodies have very low backscatter values and urban classes have consistently high backscatter values in all three dates of SAR data. Hence a simple threshold technique could mask these classes. For masking other non-agricultural classes, NDVI was computed using WiFS/AWiFS data and Kmeans classification was followed using NDVI values of the data of September to February, along with the mask of settlement and water bodies. It was assumed that the periodic changes in nonagricultural classes would be much less than those in crop classes, which have a seasonal growth pattern. This could separate the classes like, forest, wasteland and permanent vegetation. In some scenes, when the separability between the permanent vegetation and the crop classes were not distinct, the digital forest map, prepared by Forest Survey of India was used for masking forest area. This way agricultural area could be separated out. The seasonal fallow lands were included under agricultural area.

Crop classification was carried out separately for each season. September to November data was used for Kharif season crop classification, while data of November to March were used for Rabi season crop classification. For classifying crops a combination of methods were used depending upon the field situation in any scene. Suppose, in one scene, wheat, sugarcane, potato and other crop classes are available. To separate them, NDVI was computed from the data of December, January, February, March and April. An unsupervised Isodata classification was carried out. Using the ground truth information sugarcane, wheat and other crops were separated. Then, within other crop classes potato was separated from other minor crops by classifying the data of December end only. After classification of the scene, the boundaries of the districts, located within the scene were overlaid and crop statistics computed. This estimated acreage was matched with the agricultural statistics provided by Dept. of Agriculture (DOA). The classification was accepted when the area of a particular crop was within 10 percent of the DOA acreage. If the classification did not match for a single district or a group of districts within the scene, then reclassification was carried only for that group of districts. In the area, where there is mostly monocropping (a single crop mostly dominating the scene), an optimum date was selected by visually examining all the images. This optimum date's image was used for supervised classification (using groundtruth sites) of the major crop. After masking out the major crop, other crops were classified using multi-date data and Isodata classifier.

The kharif season crop was discriminated using September and October data. A decision-rule-based classifier has been used to classify multi-date SAR data and generate rice area. The concept is as described by Chakraborty and Panigrahy (1997). In this approach, logical and mathematical conditions are used to classify a pixel as crop pixel or not. In addition, qualitative tags like early, normal, late, good, poor, etc., are attached to the crop pixel (based on the outcome of the logical / mathematical conditions).

\subsubsection{Generation of cropping pattern and crop rotation maps}

Cropping pattern is defined as the yearly sequence and spatial arrangement of crops or crops and fallow, in a given area. For convenience, it is categorized on the basis of crop season as Kharif, Rabi and summer season cropping pattern. Growing two, three or four crops in a year is defined as double, triple and multiple cropping patterns. The cropping pattern maps were 
generated using a logical combination of classified images corresponding to crops grown in a season. For example, the classified channels containing map of mustard, potato, wheat, pulses, vegetables etc were combined to generate the Rabi season cropping pattern. Similarly, the image channels containing Jute, kharif rice, etc., were combined to generate the Kharif cropping pattern. The repetitive cultivation of an ordered succession of crops (or crop and fallow) on the same land is defined as crop rotation. One cycle may take one or more years to complete. It defines crop intensification in time dimension. The succeeding crop is planted after the preceding crop is harvested. The crop rotation map was generated by logical combination of the three seasonal cropping pattern maps (Panigrahy and Sharma, 1997). The class codes used to designate the crop rotation (e.g. RiceFallow-Rice (R-F-R) means Rice in Kharif season, fallow in Rabi and again, rice in summer season).

After generating seasonal cropping pattern and crop rotation maps, the district boundaries were overlaid. Then maps for seasonal cropping pattern and crop rotation were generated and area estimates for each class computed.

2.4.5 Generation of cropping system indices: Indicators are used to quantify the performance or sustainability of the agricultural practice. Several indices have been proposed to compare the efficiencies of different multiple cropping systems in terms of land use and these have been reviewed by Mengay et al., (1978). Three indices, namely, Multiple Cropping Index (MCI), Area Diversity Index (ADI) and Cultivated Land Utilization Index (CLUI) were computed. MCI measures the cropping intensity (Dalrymple 1971), ADI measures the multiplicity of crops or farm products, which are planted in a single year (Strout 1975; Wang and Yu 1975) and CLUI measures how efficiently the available land area has been used over the year (Chuang 1973). The details of the computation are given by Panigrahy et al. (2005). The remote sensing derived cropping pattern maps and crop duration information are used for computation of above indices. The historical remote sensing and statistical data aids in identifying the locations where change has occurred. All these indices were computed for each district.

Duration of each crop rotation was computed using high temporal resolution data of SPOT Vegetation (S10 NDVI products) sensor for the year 2004-5. Thirty-nine dates' data were used from $1^{\text {st }}$ May 2004 to $31^{\text {st }}$ May 2005. The NDVI profile for each cropping system in the district was fitted using growth profile model (Badhwar, 1984). From this fitted model the beginning and dates of cropping cycles were computed, considering the spectral emergence and spectral maturity date. In order to compute the total duration $\left(\mathrm{d}_{\mathrm{i}}\right)$ of a cropping system 10 days were added at the beginning ( 15 days for rice crop) and 10 days at the end of each crop-growing period. These days account for the duration of field preparation the gap between sowing and spectral emergence and the gap between spectral maturity and the harvest of the crop. The individual components viz., cropping pattern, crop rotation, indices etc., of 1998-99 and 2004-05 were compared to assess the change dynamics of the cropping systems. The differences in spatial resolution of WiFS and AWiFS (188 vs $56 \mathrm{~m})$ might add some uncertainty in the comparison, nevertheless, the magnitude of differences if sizeable, stems from the occurrence of change and not due to spatial resolution differences.

\section{RESULTS AND DISCUSSION}

\subsection{Cropping pattern}

The agricultural area of West Bengal is about $61.9 \%$ of total geographical area (TGA). The cropping systems in West Bengal state is predominantly rice based. Two important crops of kharif season are rice and jute. The fluctuation of jute crop area over years is evident from the historical statistical data. The results indicate that during the seven years time the kharif cropping pattern has almost remained same, being a rice dominant system. Jute and other kharif crops accounts for about 10 percent of the cropped area. A notable point is the decrease in the aus (autumn) rice which accounts for $5.45 \%$ of rice during 2004-5. Even the historical data of Govt. of West Bengal shows decreasing trend of aus rice. This may be attributed to readjusting of cropping system practice to suit the two crop systems in many places.

The rabi cropping pattern shows that almost all the rabi crops viz., wheat, mustard, potato and pulses/other crops have increased during 2004-05 compared to 1998-99 (table 3). The maximum increase was observed in case of mustard which grew from $3,06,443$ to $5,19,698$ ha. The potato crop area increased from $2,34,727$ to $3,74,054$ ha. The wheat area has increased from $1,82,902$ to $2,25,333$ ha. However the proportion of these crops varied within the season. The order of rabi crop proportion was mustard, followed by potato which was followed by wheat crop. The other crops which include predominantly pulses, vegetables etc show increase from $5.55 \%$ in $1998-99$ to $14.4 \%$ during 2004 05 .

\begin{tabular}{|l|r|r|r|r|}
\hline \multirow{2}{*}{ Crop } & \multicolumn{2}{|c|}{1998} & \multicolumn{2}{c|}{2004} \\
\cline { 2 - 5 } & Area (ha) & Percentage & Area (ha) & Percentage \\
\hline Potato & $2,34,727$ & 31.4 & $3,74,054$ & 28.5 \\
\hline Mustard & $3,06,443$ & 41.0 & $5,19,698$ & 39.6 \\
\hline Wheat & $1,82,902$ & 24.4 & $2,25,333$ & 17.2 \\
\hline
\end{tabular}

Table 3: Rabi crops proportion

The predominant crops in summer are boro rice, oilseeds and vegetables to a small extent. The usual area of boro rice is about 13 plus lakh ha in West Bengal state which is about $25 \%$ of kharif rice acreage. It is concentrated in midnapore, Bardhaman, 24Paraganas and Nadia districts. The boro (summer) rice area has shown marginal variation indicating the full exploitation of irrigable area for rice crop during the dry season. An increase in other crops (i.e. sesame and vegetables) was observed during summer season during 2004-05 compared to 1998-99. The reason may be attributed to better utilization of residual moisture awareness by the farmers.

\subsection{Crop Rotation}

Mapping of rotations using satellite data could only identify the major ones. The major crop rotations map was generated and fig. $2 \mathrm{a}$ and $2 \mathrm{~b}$ shows crop rotation map derived using remote sensing data for the year 1998-99 and 2004-05, respectively. The map 
shows major crop rotations and all minor rotations are clubbed into a group called 'others'. The results of comparison of rotations are given in table 4.

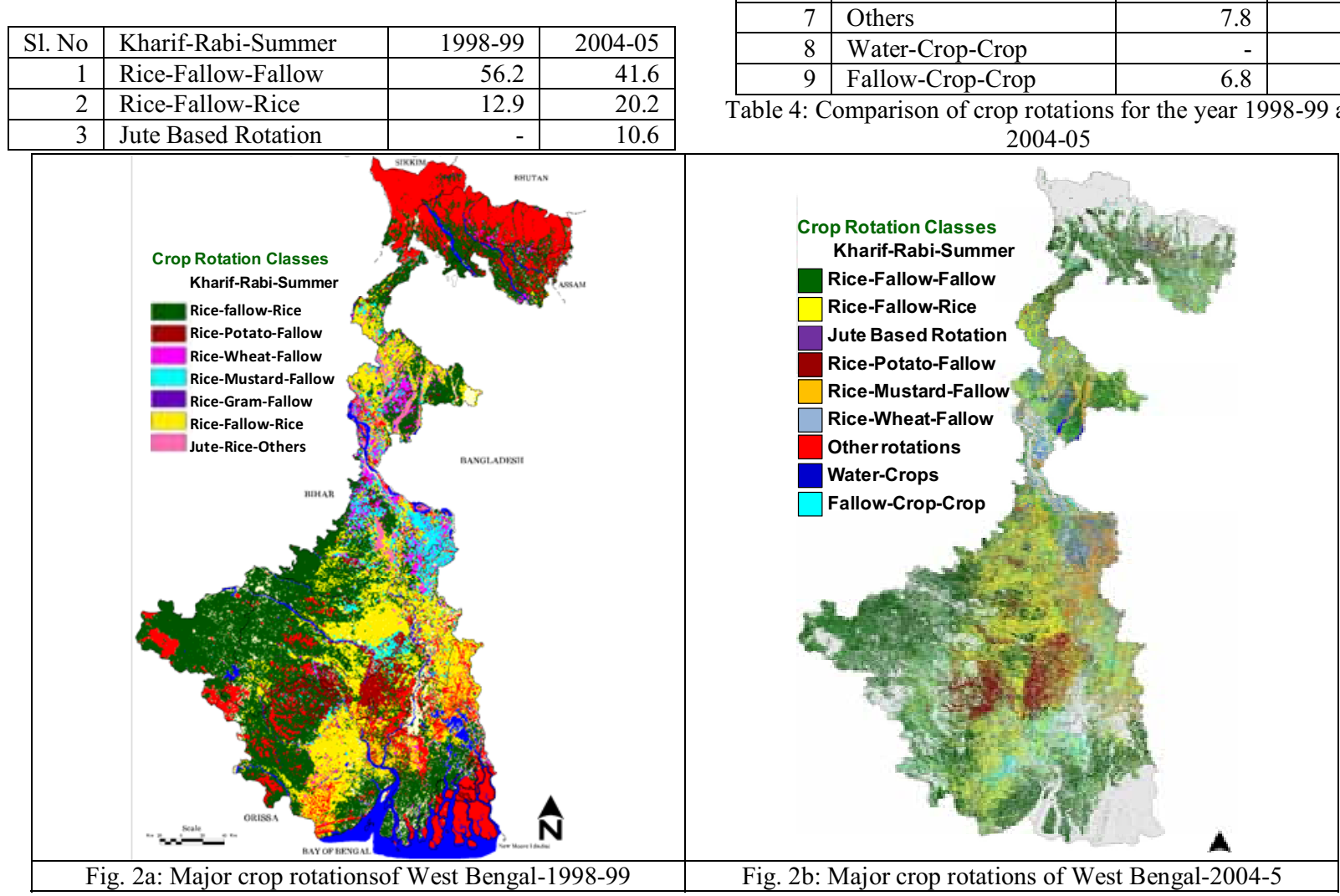

Results are indicative of changes in the cropping systems albeit short period of 7 years. The changes were more pronounced during second cropping season. Overall rice based systems were contributing to $85.5 \%$ during $1998-99$ and it increased to $91.4 \%$ during 2004-05. Marginalisation of minor cropping systems was evident from the study. R-F-F was largest rotation observed which accounted for $56.2 \%$ during 1998-99 while it decreased to $41.6 \%$ during 2004 . The jute based systems were not derived during 1998-99, therefore if we add Jute based rotations of 2004-5 to R-F-R it would results in 52.2 which still lower than 1998-99. Characteristic difference was in R-F-R systems which increased by $7 \%$. This shows the good monsoonal conditions, exploitation of available water and input resources for growing second rice crop. The rotation in which rice crop followed by potato, wheat or mustard has shown increasing trend albeit small proportion. The water-crop-crop rotation indicated that about 25 thousand ha remains waterlogged during kharif season and would be planted by crop during successive seasons. The Other and Fallow-CropCrop rotations was $14.6 \%$ in $1998-99$ which reduced to $8.3 \%$ during 2004-05. The reason for this reduction in 2004-05 is shifting of Fallow-Crop-Crop region to major rotations.

The cropping intensity is expressed as single, double and triple was computed for the study period irrespective of crops (table 5). The single cropped region reduced from $55.4 \%$ in 1998 to $49.6 \%$

\begin{tabular}{|r|l|r|r|}
\hline 4 & Rice-Potato-Fallow & 5.2 & 6.4 \\
\hline 5 & Rice-Mustard-Fallow & 7.0 & 8.8 \\
\hline 6 & Rice-Wheat-Fallow & 4.1 & 3.8 \\
\hline 7 & Others & 7.8 & 8.3 \\
\hline 8 & Water-Crop-Crop & - & 0.3 \\
\hline 9 & Fallow-Crop-Crop & 6.8 & - \\
\hline
\end{tabular}

op rotations for the year 1998-99 and . 
ISPRS Archives XXXVIII- 8/W20; Workshop Proceedings: Earth Observation for Terrestrial Ecosystems

observed predominantly in the southern part of the state. Few districts also showed decease in MCI. Cultivated land utilization index(CLUI) indicated how efficiently the available land area has been used over the year. For a cropping pattern, where the land remains unutilized for a very short period, the CLUI attains a value near to 1.0 , whereas for a completely unutilized land (throughout the year), the CLUI is 0.0. CLUI showed an increase by about 9 percent in six years. Birbhum district showed highest increase in CLUI.

\section{CONCLUSIONS}

The present study has used a unique combination of remote sensing data and ground data to generate spatial database of different cropping systems of West Bengal state of India for 1998-99 and 2004-05. It has also been possible to characterize the cropping systems with respect to their diversity and land utilization capability and assess the change dynamics over seven years. Within this short period sizeable changes were observed due to the intensification and exploring the resources for better productivity from the same land. The study has not only quantitatively assessed the changes in cropping systems; it has also identified the areas showing intensive changes. The cropping systems performance indicators at district level also showed the temporal differences. This kind of study is useful in understanding the long-term sustainability of agricultural system.

\section{REFERENCES}

Chakraborty, M. and Panigrahy, S., 2000. A processing and software system for rice crop inventory using multi-date Radarsat ScanSAR data. ISPRS Journal of Photogrammetry and Remote Sensing, 55, pp. 119-128.

Chuang, F.T. (1973). An analysis of change of Taiwan's cultivated land utilization for recent years. Rural Econ. Div., JCRR Rep. 21, Taipei, Taiwan.

\begin{tabular}{|l|r|r|r|r|r|r|r|r|r|}
\hline & \multicolumn{3}{|c|}{ ADI } & \multicolumn{3}{|c|}{ MCI } & \multicolumn{3}{c|}{ CLUI } \\
\hline District & $1998-99$ & $2004-05$ & Difference & $1998-99$ & $2004-05$ & Difference & $1998-99$ & $2004-05$ & Difference \\
\hline Bankura & 1.75 & 1.70 & -0.05 & 120.8 & 141.1 & 20.4 & 0.500 & 0.583 & 0.08 \\
\hline Bardhaman & 3.48 & 1.83 & -1.65 & 156.0 & 166.7 & 10.6 & 0.610 & 0.644 & 0.03 \\
\hline Birbhum & 2.30 & 2.20 & -0.10 & 133.5 & 164.2 & 30.6 & 0.535 & 0.645 & 0.11 \\
\hline Cooch Behar & 2.20 & 2.05 & -0.15 & 127.2 & 133.6 & 6.4 & 0.519 & 0.582 & 0.06 \\
\hline Darjeeling & 1.73 & 1.50 & -0.23 & 119.5 & 110.7 & -8.8 & 0.498 & 0.477 & -0.02 \\
\hline Dinajpur & 3.08 & 1.89 & -1.19 & 134.5 & 156.1 & 21.6 & 0.544 & 0.636 & 0.09 \\
\hline Howrah & 3.22 & 1.07 & -2.15 & 152.7 & 139.6 & -13.1 & 0.601 & 0.646 & 0.04 \\
\hline Hooghly & 3.86 & 1.66 & -2.20 & 164.7 & 195.1 & 30.4 & 0.619 & 0.717 & 0.10 \\
\hline Jalpaiguri & 1.78 & 2.25 & 0.48 & 116.6 & 120.0 & 3.4 & 0.495 & 0.514 & 0.02 \\
\hline Malda & 4.67 & 2.03 & -2.64 & 147.8 & 152.9 & 5.1 & 0.590 & 0.652 & \\
\hline Midnapur & 2.25 & 1.28 & -0.97 & 131.7 & 140.3 & 8.6 & 0.538 & 0.590 & 0.06 \\
\hline Murshidabad & 5.00 & 2.31 & -2.69 & 157.7 & 165.6 & 7.9 & 0.620 & 0.658 & 0.05 \\
\hline Nadia & 4.90 & 2.10 & -2.80 & 173.5 & 156.8 & -16.6 & 0.666 & 0.654 & 0.04 \\
\hline 24-Paragunas & 2.45 & 1.30 & -1.15 & 126.4 & 130.6 & 4.2 & 0.532 & 0.568 & -0.01 \\
\hline Purulia & 1.13 & 1.26 & 0.13 & 104.3 & 107.2 & 3.0 & 0.452 & 0.457 & 0.04 \\
\hline West Bengal & 2.85 & 1.76 & -1.08 & 137.1 & 145.4 & 8.3 & 0.553 & 0.602 & 0.01 \\
\hline
\end{tabular}

Table 6: Cropping system performance indices (1998-99 and 2004-05)
Dalrymple, D.F. (1971). Survey of multiple cropping in less developed nations. United States Department of Agriculture, Washington D.C. FEDS, 108 p.

Menegay, M.R., Hubbel, J.N. and William, R.D. (1978). Crop intensity index: A research method of measuring land use in multiple cropping. Hort Science, 13: 8-11.

Panigrahy, S., \& Sharma, S. A. (1997). Mapping of crop rotation using multidate Indian Remote Sensing Satellite digital data. ISPRS Journal of Photogram Remote Sensing, 52(2), 85-91.

Panigrahy, S., Manjunath, K.R. and Ray, S. S. (2005). Deriving cropping system performance indices using remote sensing and GIS. Int. J. Rem. Sens. 26(12): 2595-1606.

Panigrahy, S., Ray, S. S., Manjunath, K. R., Pandey, P.S., Sharma, S.K., Sood, A., Yadav, M., Gupta, P.C., Kundu, N. and Parihar, J.S. (2009). A spatial database of cropping system and its characteristics to aid to climate change impact assessment studies, pp. 150-155. The International Archives of the Photogrammetry, Remote Sensing and Spatial Information Sciences' Vol. XXXVIII Part 8/W3 (eds. Sushma Panigrahy, Shibendu Shankar Ray and Jai Singh Parihar).

Strout, A.M. (1975). Some definitional problems with multiple cropping diversification. Phil. Econ.Journal, 14: 308-316.

Wang, Y.T. and Yu, Y.H. (1975). Historical evaluation and future prospect for multiple crop diversification. Phil. Econ. J., 14: 2646.

\section{ACKNOWLEDGEMENTS}

The study was carried out as part of the ISRO EOAM project on "Cropping System Analysis". The authors are grateful to R.R. Navalgund, Director, Space Applications Centre, ISRO for his kind support and keen interest in the study. 